\title{
Antimicrobial Resistance in Hospitalized Patients with Community Acquired Urinary Tract Infection in Isfahan, Iran
}

Sayed Nassereddin Mostafavi, MD ${ }^{1,2^{*}}$; Soodabeh Rostami, PhD $^{3 *}$; Yasamin Rezaee Nejad, MD ${ }^{1}$; Behrooz Ataei, MD ${ }^{1}$; Sina Mobasherizadeh, PhD $^{3}$; Aazam Cheraghi, MSc ${ }^{4}$; Somayeh Haghighipour, MD'; Samereh Nouri, MSc ${ }^{5}$; Arezoo Pourdad, MSc ${ }^{6}$; Parisa Ataabadi, MSc ${ }^{6}$; Nasser Almasi, DMLS'; Leila Heidary, MSc ${ }^{7}$; Kourosh Naderi, MSc $^{7}$; Setareh Korangbeheshti, BSc ${ }^{7}$; Shiva Navabi, BSc ${ }^{8}$; Laleh Masssah, MSc ${ }^{8}$; Zohreh Norouzi, MSc ${ }^{8}$; Mehrnoush Bakhtiyaritabar, BSc ${ }^{8}$; Saeed Moayednia, DMLS ${ }^{5}$, Dariush Shokri, PhD³; Mahin Mikhak, DMLS; Majid Rahmani, DMLS $^{8}$; Mohammad Hashemi, MD ${ }^{9}$; Reza Etminani, MD $^{4}$; Nasrin Ahmadi, BSc ${ }^{4}$; Roya Kelishadi, MD²

\author{
'Infectious Disease and Tropical Medicine Research Center, Isfahan University of Medical Sciences, Isfahan, Iran \\ ${ }^{2}$ Child Growth and Development Research Center, Research Institute for Primordial Prevention of non-Communicable Disease, Isfahan \\ University of Medical Sciences, Isfahan, Iran \\ ${ }^{3}$ Nosocomial Infection research Center, Isfahan University of Medical Sciences, Isfahan, Iran \\ ${ }^{4}$ Vice-chancelleries for Clinical Affairs, Isfahan University of Medical Sciences, Isfahan, Iran \\ ${ }^{5}$ Department of Microbiology, Clinical Laboratory of Alzahra Medical Center, Isfahan, Iran \\ ${ }^{6}$ Alzahra Medical Center, Isfahan University of Medical Sciences, Isfahan, Iran \\ ${ }^{7}$ Dr. Shariati Hospital, Isfahan Social Security Organization, Isfahan, Iran \\ ${ }^{8}$ Dr. Gharazi Hospital, Isfahan Social Security Organization, Isfahan, Iran \\ ${ }^{9}$ Cardiovascular Department, Interventional Research Center, Isfahan University of Medical Sciences, Isfahan, Iran
}

\begin{abstract}
Background: Antibiotic resistance against uro-pathogens is a worldwide health concern. The aim of this study was to determine the causative bacteria and antibiotic susceptibility patterns among hospitalized patients with community acquired urinary tract infection (UTI).

Methods: This cross-sectional study was performed in 2016-2018 in Isfahan, Iran. Urine samples were examined for strain identification and antimicrobial resistance pattern using standard tests. Stratification was done based on gender and age $(<20$ and $>20$ years) groups. Chi-square and Fisher exact tests were applied to assess differences in etiology and susceptibility rates between groups.

Results: Among 1180 patients, Escherichia coli was the commonest pathogen (68.1\%) followed by Enterococcus spp. (8.8\%) and Klebsiella pneumonia (8.0 \%). Non-E. coli pathogens were more frequent among males $(41.8 \%$ versus $24.8 \%$ in females, $P<0.01)$ and in those aged under 20 years $(61.0 \%$ versus $22.2 \%$ in older than 20 years, $P<0.01)$. Isolated bacteria revealed high susceptibility to imipenem (94.9\%), meropenem (92.2\%), and amikacin $(91.9 \%)$; moderate sensitivity to gentamicin $(64.4 \%)$, cefepime $(52.6 \%)$ and ceftazidime $(47.2 \%)$; and low susceptibility to ceftriaxone $(41.8 \%)$, cefotaxime $(40.0 \%)$, ciprofloxacin (38.6\%) and trimethoprim-sulfamethoxazol (31.3\%). The sensitivity of isolates to ceftriaxone, ceftazidime, cefepime, imipenem, meropenem, amikacin and ciprofloxacin was significantly higher in females. Compared to the older age group, uro-pathogens were more susceptible to ciprofloxacin, ceftazidime and gentamicin in patients aged under 20 years.

Conclusion: We found that imipenem, meropenem and amikacin were good choices for empiric therapy of complicated or severe hospitalized patients with community acquired UTI; and gentamicin, cefepime and ceftazidime were acceptable as initial choices in non-severe infections in the area.

Keywords: Antimicrobial susceptibility, Community acquired, Hospitalized, Infection, Iran, Urinary tract

Cite this article as: Mostafavi SN, Rostami S, Rezaee NejadY, Ataei B, Mobasherizadeh S, Cheraghi A, et al. Antimicrobial resistance in hospitalized patients with community acquired urinary tract infection in Isfahan, Iran. Arch Iran Med. 2021;24(3):187-192. doi: 10.34172/aim.2021.29.
\end{abstract}

Received: June 2, 2020, Accepted: October 20, 2020, ePublished: March 1, 202

\section{Introduction}

Urinary tract infection (UTI) is a worldwide bacterial infection with significant mortality, morbidity, and health expenses in all ages. ${ }^{1}$ The main bacterial etiology of the infection includes Escherichia coli, Proteus sp., Pseudomonas aeruginosa, Acinetobacter spp., Klebsiella spp., Enterobacter sp., Citrobacter sp., Staphylococcus saprophyticus, Enterococcus sp., and Staphylococcus epidermidis. ${ }^{2}$

Clinical manifestations vary largely from asymptomatic or mild dysuria to high fever, vomiting, back pain, and

\footnotetext{
*Corresponding Authors: Sayed Nassereddin Mostafavi, MD; Address: Infectious Disease and Tropical Medicine Research Center, Isfahan University of Medical Sciences, Isfahan, Iran. Tel: 0098-3137923929; Fax: 0098-3137923929; Email: n_mostafavy@med.mui.ac.ir;

Soodabeh Rostami, PhD; Nosocomial Infection research Center, Isfahan University of Medical Sciences, Isfahan, Iran. Tel: 0098-3137923929; Fax: 00983137923929, Email: srostami1876@gmail.com
} 
even bacteremia, sepsis or death. ${ }^{3}$ Treatment of patients with severe or complicated disease requires hospital admission and prompt intravenous antibiotic therapy before obtaining the results of urinary culture. ${ }^{4,5}$

Unfortunately, during recent years, the increasing resistance of microorganisms to antibiotics has become a global concern; urinary pathogens are not an exception., ${ }^{6,7}$ In addition, the susceptibility pattern of uro-pathogens differs in various geographic locations and different settings, i.e. outpatient versus hospitalized, community acquired hospitalized patients versus hospital-acquired hospitalized patients. ${ }^{6-8}$ Therefore, periodic evaluation of susceptibility pattern of uro-pathogens in each area and in different settings is necessary to select the best antibiotics for empiric treatment of UTIs. ${ }^{6-9}$ According to our literature review, few studies have been performed on antibiotic susceptibility of microorganisms causing UTI in hospitalized patients all around the world, and none of them have specifically studied the community-acquired cases. $^{9-13}$

The aim of this study is to determine the etiology and total antibiotic susceptibility of community-acquired uropathogens in patients who were admitted to three large hospitals which participate in the Isfahan Antimicrobial resistance Surveillance-1(IAS-1) study.

\section{Materials and Methods}

Study Design

The study was designed to report the results of antibiotic susceptibility patterns of pathogens in patients who were admitted to hospitals because of community- acquired UTI. They were recruited during the time period of March 2016 to March 2018 and participated in the IAS-1 project which is a cross-sectional study planned to investigate the antimicrobial susceptibility profile of clinically important microorganisms, conducted in Isfahan, Iran. ${ }^{14}$

Indications for admission of the patients include hemodynamic instability, complicating factors (such as urinary stones), severe symptoms, intolerance of oral antibiotics, and poor adherence to medications. The IAS-1 study was planned to investigate the main microorganisms and antibiotic susceptibility profile of infections in cases who were admitted to three large medical centers in Isfahan city, Iran (Project No: 194042). In addition to recording antibacterial resistance of clinical isolates, it aimed to eliminate contaminant isolates, and determine healthcare/ community source of the infection by cooperation of skilled infectious control nurses and physicians in the enrolled hospitals. The study aimed to help the clinicians in selecting the most appropriate antibiotic for treatment of infections in the area. The medical centers that participate in the research were the main large hospitals of Isfahan city, i.e. Al-Zahra, Dr. Shariati and Dr. Gharazi hospitals. The laboratories of these medical centers attained Quality Credit for microbiological report from the Iranian Ministry of Health and collaborated in the Global Antimicrobial Resistance Surveillance System (GLASS) program of the World Health Organization (WHO). ${ }^{15}$

Organism Identification and Antibiotic Susceptibility Testing

Urine samples were obtained from patients with suspected UTI. UTI was defined as presence of pyuria in urine analysis ( $\geq 10 \mathrm{WBC} / \mathrm{mL}$ of urine) in addition to growth of $\geq 10^{5}$ colony count of a single urinary pathogen in one urine sample or single non-urinary pathogens in 2 urine specimen with the same resistance profile. Patients with healthcare-associated UTI were excluded from the study. Data on age, sex, nosocomial or community acquisition of the infection as well as the etiological agent and susceptibility profile of the isolated bacteria were prepared using the WHONET software.

For detection of uro-pathogens, urine samples were collected according to local hospital guidelines and were inoculated with a standard wire loop onto sheep blood agar and MacConkey agar or eosin-methylene blue agar and were incubated overnight at $37^{\circ} \mathrm{C}$. Isolation of uropathogens (E. coli, Proteus spp., Klebsiella spp., Enterobacter spp., Citrobacter spp., P. aeruginosa, Acinetobacter spp., Enterococcus spp., S. saprophyticus and S. epidermidis) was done by routine conventional methods such as catalase and oxidase test, sugar fermentation, growth on selective media, susceptibility or resistance to specific agents and other standard microbiology tests.

Antimicrobial susceptibility testing was performed using the Kirby-Bauer method, as recommended by the Clinical Laboratory Standard Institute. ${ }^{15}$ The following antibiotics were tested: cefotaxime $(30 \mu \mathrm{g})$, ceftriaxone $(30 \mu \mathrm{g})$, ceftazidime $(30 \mu \mathrm{g})$, cefepime $(30 \mu \mathrm{g})$, imipenem $(10 \mu \mathrm{g})$, meropenem $(10 \mu \mathrm{g})$, gentamicin $(10 \mu \mathrm{g})$, amikacin $(30$ $\mu \mathrm{g})$, ciprofloxacin $(5 \mu \mathrm{g})$, trimethoprim-sulfamethoxazol $(1.25-23.75 \mu \mathrm{g})$, cefoxitin $(30 \mu \mathrm{g})$, penicillin (10 units), ampicillin $(10 \mu \mathrm{g})$ and vancomycin $(30 \mu \mathrm{g})$ (Mast Group Ltd, UK). The minimum inhibitory concentrations (MICs) of vancomycin for Staphylococcus spp. were obtained by an E-test (Liofilchem, Italy), as described in the manufacturer's instructions.

\section{Statistical Analysis}

Data on age group ( $\leq 20$ years, $>20$ years), sex, etiology and antibiotic susceptibility were extracted from the WHONET version 5.6 software in each laboratory and analyzed with SPSS version 18.0. Chi-square and Fisher exact tests were applied for analysis of the study variables. $P$ value of $<0.05$ was considered as significant.

\section{Results}

A total number of 5844 urine specimens were received for culture from March 21, 2016 to March 20, 2018, of which $3586(61.4 \%)$ samples showed no growth, 284 
(4.9\%) samples were positive for fungus and yeast, 511 $(8.7 \%)$ samples were considered as contamination, and $283(4.8 \%)$ cases were nosocomial acquired. Of 1180 isolates from patients with confirmed CAI-UTI, 488 (41.4\%) belonged to males and 295 (25.0\%) were less than 20 years old.

Gram-negative bacteria represented $84.0 \%$ (991) of the isolates and E. coli was the leading pathogen $(68.1 \%)$ followed by $K$. pneumonia (8.0\%), P. aeruginosa (7.4\%) and other gram-negative rods (Acinetobacter spp., Citrobacter spp., Klebsiella spp., Enterobacter spp., Proteus sp., Stenotrophomonas maltophilia) (5.5\%) (Table 1).

Enterococcus spp. was the most frequent gram-positive pathogen (104, 8.8\%). Other gram-positives isolates included: Staphylococcus spp. (5\%), and Streptococcus spp. (2.2\%) (Table 1).

The isolated bacteria showed high susceptibility to imipenem (94.9\%), meropenem (92.2\%) and amikacin (91.9\%); moderate sensitivity to gentamicin (64.4\%), cefepime $(52.6 \%)$ and ceftazidime $(47.2 \%)$; and low sensitivity to ceftriaxone (41.8\%), cefotaxime (40.0\%), ciprofloxacin (38.6\%) and trimethoprim-sulfamethoxazol $(31.3 \%)$. Uro-pathogens in female patients had more susceptibility to imipenem, meropenem, amikacin, cefepime, ceftazidime, ceftriaxone and ciprofloxacin. In addition, in the younger age group ( $<20$ years), the isolated organisms has significantly higher susceptibility to gentamicin, ceftazidime, cefepime and ciprofloxacin
(Table 2). The antibiotic susceptibility of the common isolated bacteria is presented in Table 3 .

\section{Discussion}

Our study reveals that $E$. coli is the most common cause of community-acquired UTI in patients who need hospitalization. Furthermore, it shows a high bacterial resistance rate to several antibiotics including cefotaxime, ceftriaxone, ceftazidime, cefepime, trimethoprimsulfamethoxazole, and ciprofloxacin. In addition, it demonstrates a high susceptibility rate of causative agents to imipenem, meropenem and amikacin.

To the best of our knowledge, no earlier investigation has reported common pathogens and their sensitivity profile in hospitalized patients with community- acquired UTI. Recognition of the antibacterial susceptibility patterns of uropathogens in these patients is an essential factor for selecting a proper empirical antimicrobial treatment in each area. ${ }^{6,7}$ Previous studies on the resistance pattern of uropathogens all around the world usually did not exclude the cases of contamination ${ }^{8,10}$ or outpatient isolates from the analysis. ${ }^{10,12}$ A few investigations which were performed in hospitalized patients did not exclude the cases of healthcare-associated UTIs from their studies. ${ }^{8-13}$ To decrease the rate of contamination in final analysis, we excluded the urinary isolates with no concomitant pyuria in urinalysis. Moreover, we recognized community source of the isolates with help from experienced infectious

Table 1. Frequency of Microorganisms Causing Community-Acquired Urinary Tract Infection in Patients Hospitalized in Three Hospitals in Isfahan, Iran During 2016-2018 According to Sex and Age Groups: Results of the IAS-1 Project

\begin{tabular}{|c|c|c|c|c|c|c|c|}
\hline \multirow[b]{2}{*}{ Organisms } & \multicolumn{3}{|c|}{ Sex } & \multicolumn{3}{|c|}{ Age Group (y) } & \multirow[b]{2}{*}{ Total } \\
\hline & $\begin{array}{c}\text { Male } \\
\text { No. }(\%)\end{array}$ & $\begin{array}{c}\text { Female } \\
\text { No. }(\%)\end{array}$ & $\begin{array}{c}\text { OR }(95 \% \mathrm{Cl}) \\
P \text { Value }^{\mathrm{a}}\end{array}$ & $\begin{array}{c}<20 \\
\text { No. }(\%)\end{array}$ & $\begin{array}{c}>20 \\
\text { No. }(\%)\end{array}$ & $\begin{array}{c}\text { OR }(95 \% \mathrm{Cl}) \\
P \text { Value }\end{array}$ & \\
\hline E. coli & $\begin{array}{c}284 \\
(58.19)\end{array}$ & $\begin{array}{c}520 \\
(75.14)\end{array}$ & $\begin{array}{c}0.342(0.267-0.438) \\
<0.001\end{array}$ & $\begin{array}{c}115 \\
(38.98)\end{array}$ & $\begin{array}{c}689 \\
(77.85)\end{array}$ & $\begin{array}{c}0.182(0.137-0.241) \\
<0.001\end{array}$ & $\begin{array}{c}804 \\
(68.13)\end{array}$ \\
\hline K. pneumonia & $\begin{array}{c}46 \\
(9.42)\end{array}$ & $\begin{array}{c}48 \\
(6.93)\end{array}$ & $\begin{array}{c}1.396(0.915-2.130) \\
0.120\end{array}$ & $\begin{array}{c}87 \\
(29.49)\end{array}$ & $\begin{array}{c}7 \\
(0.79)\end{array}$ & $\begin{array}{c}52.463(23.93-114.987) \\
<0.001\end{array}$ & $\begin{array}{c}94 \\
(7.96)\end{array}$ \\
\hline$P$. aeruginosa & $\begin{array}{c}19 \\
(3.89)\end{array}$ & $\begin{array}{c}9 \\
(1.30)\end{array}$ & $\begin{array}{c}3.074(1.379-6.854) \\
0.004\end{array}$ & $\begin{array}{c}23 \\
(7.79)\end{array}$ & $\begin{array}{c}5 \\
(0.56)\end{array}$ & $\begin{array}{c}14.882(5.604-39.520) \\
<0.001\end{array}$ & $\begin{array}{c}28 \\
(2.37)\end{array}$ \\
\hline Other gram-negative organisms ${ }^{b}$ & $\begin{array}{c}42 \\
(8.60)\end{array}$ & $\begin{array}{c}23 \\
(3.32)\end{array}$ & $\begin{array}{c}2.739(1.625-4.618) \\
<0.001\end{array}$ & $\begin{array}{c}61 \\
(20.67)\end{array}$ & $\begin{array}{c}4 \\
(0.45)\end{array}$ & $\begin{array}{c}56.451(20.322-156.813) \\
<0.001\end{array}$ & $\begin{array}{c}65 \\
(5.50)\end{array}$ \\
\hline Total gram-negative organisms & $\begin{array}{c}391 \\
(80.12)\end{array}$ & $\begin{array}{c}600 \\
(86.70)\end{array}$ & $\begin{array}{c}0.618(0.452-0.845) \\
0.002\end{array}$ & $\begin{array}{c}286 \\
(96.94)\end{array}$ & $\begin{array}{c}705 \\
(79.66)\end{array}$ & $\begin{array}{c}8.113(4.096-16.070) \\
<0.001\end{array}$ & $\begin{array}{c}991 \\
(83.98)\end{array}$ \\
\hline Enterococcus spp. & $\begin{array}{c}56 \\
(11.47)\end{array}$ & $\begin{array}{c}48 \\
(6.93)\end{array}$ & $\begin{array}{c}1.739(1.161-2.606) \\
0.007\end{array}$ & $\begin{array}{c}4 \\
(1.35)\end{array}$ & $\begin{array}{c}100 \\
(11.29)\end{array}$ & $\begin{array}{c}0.108(0.39-0.296) \\
<0.001\end{array}$ & $\begin{array}{c}104 \\
(8.81)\end{array}$ \\
\hline Staphylococcus spp. & $\begin{array}{c}30 \\
(6.14)\end{array}$ & $\begin{array}{c}29 \\
(4.19)\end{array}$ & $\begin{array}{c}1.498(0.887-2.529) \\
0.129\end{array}$ & $\begin{array}{c}4 \\
(1.35)\end{array}$ & $\begin{array}{c}55 \\
(6.21)\end{array}$ & $\begin{array}{c}0.207(0.75-0.577) \\
0.001\end{array}$ & $\begin{array}{l}59 \\
(5)\end{array}$ \\
\hline Streptococcus spp. & $\begin{array}{c}11 \\
(2.25)\end{array}$ & $\begin{array}{c}15 \\
(2.16)\end{array}$ & $\begin{array}{c}1.041(0.474-2.286) \\
0.921\end{array}$ & $\begin{array}{c}1 \\
(0.33)\end{array}$ & $\begin{array}{c}25 \\
(2.82)\end{array}$ & $\begin{array}{c}0.117(0.16-0.867) \\
0.010\end{array}$ & $\begin{array}{c}26 \\
(2.20)\end{array}$ \\
\hline Total gram-positive organisms ${ }^{c}$ & $\begin{array}{c}97 \\
(19.86)\end{array}$ & $\begin{array}{c}92 \\
(13.29)\end{array}$ & $\begin{array}{c}1.618(1.184-2.211) \\
0.002\end{array}$ & $\begin{array}{c}9 \\
(3.05)\end{array}$ & $\begin{array}{c}180 \\
(20.33)\end{array}$ & $\begin{array}{c}0.123(0.062-0.244) \\
<0.001\end{array}$ & $\begin{array}{c}189 \\
(16.01)\end{array}$ \\
\hline Total organisms & $\begin{array}{c}488 \\
(100)\end{array}$ & $\begin{array}{c}692 \\
(100)\end{array}$ & - & $\begin{array}{c}295 \\
(100)\end{array}$ & $\begin{array}{c}885 \\
(100)\end{array}$ & - & $\begin{array}{l}1180 \\
(100)\end{array}$ \\
\hline
\end{tabular}

a $P$ value obtained from chi-square test if expected cell count was greater than 5 and Fisher exact test if expected cell count was less than 5 .

${ }^{\mathrm{b}}$ Including Acinetobacter spp., Citrobacter spp., Klebsiella spp., Enterobacter spp., Proteus sp., and Stenotrophomonas maltophilia

c Including Staphylococcus spp., and Streptococcus spp. 
Table 2. Antimicrobial Sensitivity of Microorganisms Causing Community-Acquired Urinary Tract Infection in Patients Hospitalized in Three Hospitals in Isfahan, Iran During 2016-2018 According to Sex and Age Groups: Results of the IAS-1 Project

\begin{tabular}{|c|c|c|c|c|c|c|c|}
\hline \multirow[b]{2}{*}{ Antibiotic } & \multicolumn{3}{|c|}{ Sex } & \multicolumn{3}{|c|}{ Age Group } & \multirow[b]{2}{*}{ Total } \\
\hline & $\begin{array}{c}\text { Male } \\
\text { No. }(\%)\end{array}$ & Female & $\begin{array}{c}\text { OR }(95 \% \mathrm{CI}) \\
P \text { Value }\end{array}$ & $<\mathbf{2 0}$ & $>\mathbf{2 0}$ & $\begin{array}{c}\text { OR }(95 \% \mathrm{Cl}) \\
P \text { Value }\end{array}$ & \\
\hline Cefazolin & $\begin{array}{c}47 / 167 \\
(28.1)\end{array}$ & $\begin{array}{c}123 / 303 \\
(40.6)\end{array}$ & $\begin{array}{c}0.965(0.649-1.435) \\
0.860\end{array}$ & $\begin{array}{l}31 / 83 \\
(37.3)\end{array}$ & $\begin{array}{c}139 / 387 \\
(35.9)\end{array}$ & $\begin{array}{c}0.892(0.553-1.440) \\
0.640\end{array}$ & $\begin{array}{c}170 / 470 \\
(36.1)\end{array}$ \\
\hline Cefotaxime & $\begin{array}{c}71 / 177 \\
(40.1)\end{array}$ & $\begin{array}{c}125 / 313 \\
(39.9)\end{array}$ & $\begin{array}{c}1.007(0.692-1.467) \\
0.969\end{array}$ & $\begin{array}{l}33 / 82 \\
(40.2)\end{array}$ & $\begin{array}{l}164 / 408 \\
(40)\end{array}$ & $\begin{array}{c}1.002(0.618-1.625) \\
0.994\end{array}$ & $\begin{array}{c}196 / 490 \\
(40)\end{array}$ \\
\hline Ceftriaxone & $\begin{array}{c}74 / 187 \\
(39.6)\end{array}$ & $\begin{array}{c}130 / 300 \\
(43.3)\end{array}$ & $\begin{array}{c}0.517(0.364-0.737) \\
<0.001\end{array}$ & $\begin{array}{l}37 / 83 \\
(44.6)\end{array}$ & $\begin{array}{c}167 / 404 \\
(41.3)\end{array}$ & $\begin{array}{c}1.141(0.709-1.837) \\
0.586\end{array}$ & $\begin{array}{c}204 / 487 \\
(41.8)\end{array}$ \\
\hline Ceftazidime & $\begin{array}{c}144 / 356 \\
(40.4)\end{array}$ & $\begin{array}{c}274 / 528 \\
(51.9)\end{array}$ & $\begin{array}{c}0.630(0.480-0.826) \\
<0.001\end{array}$ & $\begin{array}{c}60 / 113 \\
(53.1)\end{array}$ & $\begin{array}{c}358 / 771 \\
(46.4)\end{array}$ & $\begin{array}{c}2.438(1.650-3.602) \\
<0.001\end{array}$ & $\begin{array}{c}418 / 884 \\
(47.2)\end{array}$ \\
\hline Cefepime & $\begin{array}{c}154 / 341 \\
(45.2)\end{array}$ & $\begin{array}{c}289 / 501 \\
(57.7)\end{array}$ & $\begin{array}{c}0.604(0.458-0.797) \\
<0.001\end{array}$ & $\begin{array}{c}63 / 105 \\
(60)\end{array}$ & $\begin{array}{c}381 / 737 \\
(51.6)\end{array}$ & $\begin{array}{c}1.402(0.924-2.125) \\
0.111\end{array}$ & $\begin{array}{c}443 /(842 \\
(52.6)\end{array}$ \\
\hline Imipenem & $\begin{array}{c}264 / 287 \\
(92)\end{array}$ & $\begin{array}{c}430 / 444 \\
(96.8)\end{array}$ & $\begin{array}{c}0.374(0.189-0.739) \\
0.003\end{array}$ & $\begin{array}{l}90 / 94 \\
(95.7)\end{array}$ & $\begin{array}{c}604 / 637 \\
(94.8)\end{array}$ & $\begin{array}{c}1.229(0.425-3.552) \\
0.702\end{array}$ & $\begin{array}{c}694 / 731 \\
(94.9)\end{array}$ \\
\hline Meropenem & $\begin{array}{c}220 / 253 \\
(87)\end{array}$ & $\begin{array}{l}360 / 376 \\
(95.7)\end{array}$ & $\begin{array}{c}5.852(3.939-8.694) \\
<0.001\end{array}$ & $\begin{array}{l}91 / 95 \\
(95.8)\end{array}$ & $\begin{array}{c}489 / 637 \\
(94.8)\end{array}$ & $\begin{array}{c}6.885(2.488-19.057) \\
<0.001\end{array}$ & $\begin{array}{c}580 / 629 \\
(92.2)\end{array}$ \\
\hline Amikacin & $\begin{array}{c}307 / 348 \\
(88.2)\end{array}$ & $\begin{array}{c}478 / 506 \\
(94.5)\end{array}$ & $\begin{array}{c}0.439(0.266-0.724) \\
0.001\end{array}$ & $\begin{array}{c}102 / 110 \\
(92.7)\end{array}$ & $\begin{array}{c}683 / 744 \\
(91.8)\end{array}$ & $\begin{array}{c}1.139(0.529-2.449) \\
0.739\end{array}$ & $\begin{array}{c}785 / 854 \\
(91.9)\end{array}$ \\
\hline Gentamicin & $\begin{array}{c}155 / 253 \\
(61.3)\end{array}$ & $\begin{array}{c}270 / 406 \\
(66.5)\end{array}$ & $\begin{array}{c}0.797(0.575-1.104) \\
0.172\end{array}$ & $\begin{array}{c}74 / 100 \\
(74.0)\end{array}$ & $\begin{array}{c}351 / 559 \\
(62.8)\end{array}$ & $\begin{array}{c}1.687(1.045-2.722) \\
0.031\end{array}$ & $\begin{array}{c}425 / 659 \\
(64.4)\end{array}$ \\
\hline Ciprofloxacin & $\begin{array}{c}132 / 450 \\
(29.3)\end{array}$ & $\begin{array}{c}283 / 623 \\
(45.4)\end{array}$ & $\begin{array}{c}0.499(0.386-0.645) \\
0.000\end{array}$ & $\begin{array}{c}72 / 104 \\
(69.2)\end{array}$ & $\begin{array}{c}343 / 969 \\
(35.4)\end{array}$ & $\begin{array}{c}4.106(2.653-6.355) \\
<0.001\end{array}$ & $\begin{array}{l}415 / 1073 \\
(38.6)\end{array}$ \\
\hline $\begin{array}{l}\text { Trimethoprim } \\
\text { sulfamethoxazol }\end{array}$ & $\begin{array}{c}85 / 296 \\
(28.7)\end{array}$ & $\begin{array}{c}158 / 478 \\
(33.1)\end{array}$ & $\begin{array}{c}0.816(0.595-1.119) \\
0.206\end{array}$ & $\begin{array}{c}35 / 113 \\
(31)\end{array}$ & $\begin{array}{c}208 / 661 \\
(31.5)\end{array}$ & $\begin{array}{c}0.816(0.595-1.119) \\
0.917\end{array}$ & $\begin{array}{c}243 / 774 \\
(31.3)\end{array}$ \\
\hline Nitrofurantoin & $\begin{array}{c}231 / 285 \\
(81.1)\end{array}$ & $\begin{array}{c}385 / 447 \\
(86.1)\end{array}$ & $\begin{array}{c}0.689(0.462-1.027) \\
0.067\end{array}$ & $\begin{array}{c}100 / 106 \\
(94.3)\end{array}$ & $\begin{array}{c}516 / 626 \\
(82.4)\end{array}$ & $\begin{array}{c}3.553(1.520-8.305) \\
0.002\end{array}$ & $\begin{array}{c}616 / 732 \\
(84.1)\end{array}$ \\
\hline
\end{tabular}

a $P$ value obtained from chi-square test if expected cell count was greater than 5 and Fisher exact test if expected cell count was less than 5 .

Table 3. Antimicrobial Sensitivity of Major Microorganisms Causing Community-Acquired Urinary Tract Infection in Patients Hospitalized in Three Hospitals in Isfahan, Iran During 2016-2018 According to Etiology of the Infections: Results of the IAS-1 project

\begin{tabular}{|c|c|c|c|c|}
\hline \multirow{2}{*}{$\begin{array}{l}\text { Antibiotic [Number of Sensitive/Total } \\
\text { Examined Isolates }(\%)]\end{array}$} & \multicolumn{4}{|c|}{ Etiology (Total Isolates) } \\
\hline & E. coli $(804)$ & K. pneumonia (94) & Enterococcus spp. (104) & Staphylococcus spp. (59) \\
\hline Cefotaxime & $167 / 418(40)$ & $15 / 42(35.7)$ & - & - \\
\hline Ceftriaxone & 134/337 (39.8) & $14 / 37(37.8)$ & - & - \\
\hline Ceftazidim & $348 / 718(48.5)$ & $31 / 85$ (36.5) & - & - \\
\hline Cefepime & $320 / 604(53)$ & $32 / 79(40.5)$ & - & - \\
\hline Imipenem & $598 / 611(97.9)$ & $46 / 56(82.1)$ & - & - \\
\hline Meropenem & $411 / 419(98.1)$ & $45 / 61(73.8)$ & - & - \\
\hline Amikacin & $593 / 618(96)$ & $72 / 88(81.8)$ & - & - \\
\hline Gentamicin & $314 / 478(65.7)$ & $24 / 39(61.5)$ & 25/41 (61.0) & $34 / 50(68.0)$ \\
\hline Ciprofloxacin & 286/732 (39.1) & $32 / 88(36.4)$ & $26 / 96(27.1)$ & $31 / 55(56.4)$ \\
\hline Trimethoprim- sulfamethoxazol & $183 / 597(30.7)$ & 23/68 (33.8) & $0 / 3(0.0)$ & $26 / 54(48.1)$ \\
\hline Vancomycin & - & - & $62 / 86(72.1)$ & $45 / 45(100)$ \\
\hline Ampicillin & $55 / 681(8.1)$ & $1 / 34(2.9)$ & $58 / 96(60.4)$ & - \\
\hline Penicillin G & - & - & $16 / 34(47.1)$ & - \\
\hline Cefoxitin & - & - & - & $24 / 46(52.2)$ \\
\hline
\end{tabular}

control nurses at the bed of patients in enrolled hospitals. ${ }^{14}$

The sex pattern of patients in our study reveals relatively equal distribution in both sexes. Approximately $41 \%$ of admitted patients in our study were males. This finding is in accordance with findings of previous researches in hospitalized patients with UTI. ${ }^{8,9}$

In our study, consistent with some other investigations, the most frequent bacterium in the UTI cases was E. coli, accounting for $68.1 \%$ of the isolates. The percentage of the isolate is comparable to those reported in several former investigations. ${ }^{10}$ Enterococcus spp. was the second most common organism followed by Klebsiella spp. and Staphylococcus spp. Our study is different from some researches that reported Klebsiella spp. or other Gram- 
negative rods as the second most prevalent urinary pathogen. As we included only hospitalized patients with community- acquired UTI in the analysis, the finding could be different from other investigations that had included outpatient cases ${ }^{12,13}$ or nosocomial hospitalized individuals. ${ }^{10,11,12,16}$

Our study, in accordance with findings of some previous investigations, shows that non- $E$. coli uro-pathogens were significantly more common in male $e^{8,9,10}$ and younger $(<20$ years) UTI cases. ${ }^{8}$

The most effective antibiotics in our study were carbapenems (imipenem, meropenem) and amikacin. This finding can suggest them as the first line for empiric treatment of hospitalized UTI patients with severe symptoms in the area.

Carbapenems are effective drugs for multidrug resistant (MDR) Enterobacteriaceae, and our results are in agreement with the frequency of resistance to these antibiotics from earlier studies in Canada, Greece, and India (less than 10\%). ${ }^{10-12}$ However, due to the frequent administration of the drugs in recent years, resistance to this class of antibacterial medications is growing. ${ }^{17}$ Therefore, carbapenems should be kept for empiric therapy of severely ill patients with UTI. However, after obtaining the culture results, another appropriate antibiotic might be started.

Amongst aminoglycosides, we found that amikacin had high activity against urinary pathogens, as described in previous studies. ${ }^{9,11,12}$ More than $90 \%$ of the isolates showed susceptibility to this medication in disk diffusion test. Amikacin has a dose-dependent bactericidal activity, achieves enough concentrations in renal parenchyma and can be administered via the intramuscular route; thus, it could be a good suggestion for treatment of patients who cannot tolerate oral medications and are planned to be treated in an outpatient setting. ${ }^{18,19}$ However, because of the nephrotoxicity of this medication, administration of amikacin for treatment of renal infections has decreased in recent years. ${ }^{18,19}$

In our study, the sensitivity of isolates to gentamicin was about $64 \%$. This finding is in concordance with the study in Bosnia ${ }^{13}$ and in contrast to previous studies in Iran and Canada that reported more than $90 \%$ susceptibility of urine pathogens to this antibiotic., ${ }^{910}$ These differences are probably due to difference in year of the research or difference in antibiotic prescription in different societies. ${ }^{20}$

Our analysis revealed that urinary isolates were highly resistant to cefotaxime $(60.0 \%)$, ceftriaxone $(58.2 \%)$, ceftazidime $(52.8 \%)$, and cefepime $(47.3 \%)$, therefore making these antibiotics unsuitable for empiric treatment of UTI in severely ill inpatient cases. These findings should be considered in spite of the fact that cephalosporins are amongst the most commonly prescribed medications for treatment of UTI all around the world. This high resistance rate to cephalosporins was also reported in previous studies conducted in Iran. ${ }^{9}$ However, reports from the USA, Canada, and Greece have shown susceptibility rates of greater than $90 \%$ in urinary isolates; this might be because of the difference in the study time or geographical settings..$^{8,10,11}$

Ciprofloxacin and other fluoroquinolones are broadly prescribed for treatment of upper and lower UTIs in recent years. ${ }^{21}$ We found a low susceptibility rate of uropathogens to ciprofloxacin $(38.6 \%)$. Therefore, this agent is not appropriate for empirical treatment of inpatient UTI cases and should be reserved for de-escalation therapy, after confirmation of sensitivity of uropathogen to it, based on the opportunity of its oral usage. ${ }^{21}$ This finding is consistent with previous researches performed in Iran and Bosnia, ${ }^{9,13}$ and in contrast to reports from the USA and Canada. ${ }^{8,10}$

In our study, most of the isolates (68.7\%) showed resistance to trimethoprim-sulfamethoxazole, as reported in previous investigations in Iran, India, and Bosnia. ${ }^{9,12,13}$ Extensive use of this antibiotic in outpatients with urinary or respiratory tract infections could explain this high level of resistance in different communities. ${ }^{20,21}$ However, as this medication has an oral formulation, it would be a good choice for de-escalation therapy and for completion of the duration of therapy. This high level of resistance to trimethoprim-sulfamethoxazole was previously reported from a study in Bosnia. ${ }^{13}$ In some earlier studies, urinary isolates had better susceptibility to this agent, probably due to the time and location of the research ${ }^{8,10,11}$ or inclusion of outpatient cases in the final analysis. ${ }^{10}$

Our study had some limitations. First, our investigation was performed in three referral and large hospitals; thus, generalization of the results to all hospitalized patients with UTI should be done with caution. The second limitation is that the study was laboratory-based and information on previous antibiotic administration or anatomical abnormalities of the patients is lacking. Such data could provide meaningful clues to allow a better understanding of the sensitivity pattern of causative bacteria in clinical settings. The third is that our data were extracted from the routine work of the clinical laboratories and all antibiotic disks and strips were not available at the time of isolation of the bacteria. So, all microorganisms were not tested by all antibiotic disks and strips.

\section{Conclusion}

Our data revealed that E. coli, Enterococcus spp. and $K$. pneumonia were the predominant isolates among hospitalized patients with community-acquired UTI. In addition, we found a high susceptibility rate of uropathogens to imipenem, meropenem, and amikacin, suggesting them as good choices for empiric therapy of complicated or severe infections. Moderate sensitivity to gentamicin, cefepime, and ceftazidime suggests them as 
acceptable initial therapy in non-severe cases; while low susceptibility to cefotaxime, ceftriaxone, ciprofloxacin, and trimethoprim- sulfamethoxazole makes them unsuitable for empiric therapy of inpatients with communityacquired UTI in the area.

\section{Authors' Contribution}

SNM was the main investigator and proposed the main idea, designed the study, wrote the protocols and guidelines and revised the manuscript. SR was project manager and collected the data. YR analyzed the data and wrote the first draft of the manuscript. BA, $\mathrm{SM}, \mathrm{ACh}, \mathrm{SH}, \mathrm{MH}, \mathrm{RE}, \mathrm{NA}, \mathrm{SM}, \mathrm{MM}$ and RK were members of the Scientific committee. SN, AP, PA, NA, LH, KN, SK, ShN, LM, ZN, $M B, D S H$, and $M R$ were members of the executive committee.

\section{Conflict of Interest Disclosures}

None declared.

\section{Ethical Statement}

The research protocols were reviewed and approved by the Institutional Review Board of Isfahan University of Medical Sciences (Approval number: IR.MUI.MED.REC.1398.232).

\section{Funding}

This work was supported by Infectious Disease and Tropical Medicine Research Center, Isfahan University of Medical Sciences, Isfahan, Iran (grant number: 398324).

\section{Acknowledgements}

We acknowledge all nursing and laboratory staff of the three collaborative hospitals and administrators of Isfahan Social Security Organization for their contribution to this research. The authors have no conflict of interest in regard to the study. We also thank Mrs. Mahboubeh Akhlaghi PhD student in Biostatistics for her assistance in design of statistical analysis.

\section{References}

1. Öztürk R, Murt A. Epidemiology of urological infections: a global burden. World J Urol. 2020;38(11):2669-79. doi: 10.1007/s00345-019-03071-4.

2. Chiu CC, Lin TC, Wu RX, Yang YS, Hsiao PJ, Lee Y, et al. Etiologies of community-onset urinary tract infections requiring hospitalization and antimicrobial susceptibilities of causative microorganisms. J Microbiol Immunol Infect. 2017;50(6):879-85. doi: 10.1016/j.jmii.2016.08.008.

3. Chu CM, Lowder JL. Diagnosis and treatment of urinary tract infections across age groups. Am J Obstet Gynecol. 2018;219(1):40-51. doi: 10.1016/j.ajog.2017.12.231.

4. Chaudhari PP, Monuteaux MC, Bachur RG. Management of urinary tract infections in young children: balancing admission with the risk of emergency department revisits. Acad Pediatr. 2019;19(2):203-8. doi: 10.1016/j.acap.2018.05.011.

5. Oh MM, Kim JW, Park MG, Kim JJ, Yoo KH, Moon G. The impact of therapeutic delay time on acute scintigraphic lesion and ultimate scar formation in children with first febrile UTI. Eur J Pediatr. 2012;171(3):565-70. doi: 10.1007/s00431-0111614-3.

6. Paul R. State of the Globe: Rising Antimicrobial Resistance of Pathogens in Urinary Tract Infection. J Glob Infect Dis. 2018;10(3):117-118. doi: 10.4103/jgid.jgid_104_17.

7. Sweileh WM, Al-Jabi SW, Zyoud SH, Sawalha AF, Abu-Taha AS. Global research output in antimicrobial resistance among uropathogens: a bibliometric analysis (2002-2016). J Glob
Infect Dis. 2018;10(3):117-8. doi: 10.4103/jgid.jgid_104_17. 8. Saperston KN, Shapiro DJ, Hersh AL, Copp HL. A comparison of inpatient versus outpatient resistance patterns of pediatric urinary tract infection. J Urol. 2014;191(5 Suppl):1608-13. doi: 10.1016/j.juro.2013.10.064.

9. Nozarian Z, Abdollahi A. Microbial etiology and antimicrobial susceptibility of bacteria implicated in urinary tract infection in Tehran, Iran. Iran J Pathol. 2015;10(1):54-60.

10. Karlowsky JA, Lagacé-Wiens PR, Simner PJ, DeCorby MR, Adam HJ, Walkty A, et al. Antimicrobial resistance in urinary tract pathogens in Canada from 2007 to 2009: CANWARD surveillance study. Antimicrob Agents Chemother. 2011;55(7):3169-75. doi: 10.1128/AAC.00066-11.

11. Mantadakis E, Vouloumanou EK, Panopoulou M, Tsouvala E, Tsalkidis A, Chatzimichael A, et al. Susceptibility patterns of uropathogens identified in hospitalised children with community- acquired urinary tract infections in Thrace, Greece. J Glob Antimicrob Resist. 2015;3(2):85-90. doi: 10.1016/j.jgar.2015.02.006.

12. Pai V, Nair B. Etiology and sensitivity of uropathogens in outpatients and inpatients with urinary tract infection: Implications on empiric therapy. Ann Trop Med Public Health 2012;5:181-4

13. Ljuca S, Zvizdic S, Hamzic S, Kalajdzija M, Ljuca A. Antimicrobial susceptibility of bacteria isolated from inpatients and outpatients urine samples. Med Arh. 2010;64(3):161-4.

14. Mostafavi SN, Rostami S, Ataei B, Mobasherizadeh S, Cheraghi A, Haghighipour S, et al. Methodology and early results of the first surveillance program on prevention and control of antimicrobial resistance in Isfahan, Iran: The IAS-I study. Int J Prev Med. 2020;11:137. doi: 10.4103/ijpvm.IJPVM_189_19.

15. Clinical and Laboratory Standards Institute. Performance standards for antimicrobial susceptibility testing; 22nd-24nd informational supplement. 2015-2017, CLSI M100-S25.

16. Mortazavi-Tabatabaei SAR, Ghaderkhani J, Nazari A, Sayehmiri K, Sayehmiri F, Pakzad I. Pattern of Antibacterial Resistance in Urinary Tract Infections: A Systematic Review and Meta-analysis. Int J Prev Med. 2019;10:169. doi: 10.4103/ ijpvm.IJPVM_419_17.

17. Ssekatawa K, Byarugaba DK, Wampande E, and et al. A systematic review: the current status of carbapenem resistance in East Africa. BMC Res Notes. 2018;11(1):629. doi: 10.1186/ s13104-018-3738-2.

18. Goodlet KJ, Benhalima FZ, Nailor MD. A systematic review of single-dose aminoglycoside therapy for urinary tract infection: is it time to resurrect an old strategy? Antimicrob Agents Chemother. 2018;63(1):e02165-18. doi: 10.1128/ AAC.02165-18.

19. Ipekci T, Seyman D, Berk H, Celik O. Clinical and bacteriological efficacy of amikacin in the treatment of lower urinary tract infection caused by extended-spectrum beta-lactamase-producing Escherichia coli or Klebsiella pneumoniae. J Infect Chemother. 2014;20(12):762-7. doi: 10.1016/j.jiac.2014.08.007.

20. Goossens H, Ferech M, Vander Stichele R, Elseviers M; ESAC Project Group. Outpatient antibiotic use in Europe and association with resistance: a cross-national database study. Lancet. 2005;365(9459):579-87. doi: 10.1016/S01406736(05)17907-0.

21. Stuck AK, Täuber MG, Schabel M, Lehmann T, Suter H, Mühlemann K. Determinants of quinolone versus trimethoprim-sulfamethoxazole use for outpatient urinary tract infection. Antimicrob Agents Chemother. 2012;56(3):135963. doi: 10.1128/AAC.05321-11. 